Review

\title{
Insights into Brain Signal Transduction can Provide Potential Molecular Targets to Approach and Manage Alzheimer's Disease
}

\author{
Vincenza Rita Lo Vasco
}

Experimental and Clinical Medicine Department, University of Florence, Largo Brambilla 3, 50134 Florence, Italy; E-Mail: ritalovasco@hotmail.it

* Correspondence: Vincenza Rita Lo Vasco; E-Mail: ritalovasco@hotmail.it

Academic Editors: Golam Sharoar and Michael Wu

Special Issue: $\underline{\text { Alzheimer's Disease Research }}$

OBM Neurobiology

2020, volume 4, issue 2

doi:10.21926/obm.neurobiol.2002058
Received: October 01, 2019

Accepted: May 10, 2020

Published: May 18, 2020

\begin{abstract}
Mechanisms leading to neuronal cell death in human pathology are far from being fully delineated. Understanding the molecules involved in neuronal death and the timing of their recruitment might help to explain the natural history of degenerative processes, including the morphological abnormalities observed in Alzheimer's disease (AD). Moreover, it might help refine the diagnosis by defining new molecular markers as well as find effective therapies, especially for slow cognitive deficits, often associated with neurodegenerative diseases. Disturbances in signal transduction in neurons underlie human cognitive decline. Numerous studies have analyzed the different signal transduction pathways in $A D$, offering interesting insights into its etiology and prospective therapies. For example, studies revealed that $A D$ is associated with abnormal neuronal $\mathrm{Ca}^{2+}$ homeostasis, and that signal transduction pathways are involved in $\mathrm{Ca}^{2+}$ metabolism and phosphorylative regulation of proteins. Understanding the role and timing of action of the signaling pathways recruited during the changes in brain morphology in AD progression might help elucidate the pathogenesis of the disease, paving the way for early diagnosis, prognosis refinement, and novel molecular therapeutic strategies. In this review, we discuss the different signal transduction pathways involved in $A D$ pathogenesis.
\end{abstract}

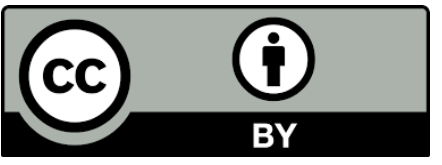

(C) 2020 by the author. This is an open access article distributed under the conditions of the Creative Commons by Attribution License, which permits unrestricted use, distribution, and reproduction in any medium or format, provided the original work is correctly cited. 


\section{Keywords}

Alzheimer; morphology; signal transduction; phos pholipase C; Wnt; PCG1; PS genes

\section{Introduction}

Alzheimer's disease (AD) is one of the common neurodegenerative diseases and a leading cause of dementia in elderly people. More than 30 million people are affected by AD worldwide. Besides elderly people, 200,000 people younger than 65 years of age are affected by young-onset AD. By 2050 , one new case of $A D$ is expected to develop every 33s, with an expected total estimated prevalence of 13.8 million [1]. AD comprises of symptoms such as memory loss, progressive impairment of mental and behavioral skills, a decline of cognitive functions, and deficits in learning abilities, ultimately resulting in dementia [2].

The etiology of $A D$ is far from being fully understood. Evidence suggests a genetic predisposition for the pathogenesis of $A D[3,4]$. Although most diagnosed $A D$ incidences are sporadic (SAD), about 1-2\% displays familial recurrence (FAD). SAD and FAD do not have any significant pathological differences, except that FAD generally has early-onset and progresses more rapidly [13]. Genetic factors influencing the onset of FAD include a mutation in the genes of $\beta$-amyloid precursor protein (APP) or of presenilin (PS1 or PS2) [2].

In less than $5 \%$ of the patients, $A D$ co-segregates with specific mutations in $\beta$-APP, PS1, and PS2 $[3,4]$. The extracellular deposits or plaques of amyloid- $\beta(A \beta)$ peptides and intraneuronal neurofibrillary tangles (NFTs) of abnormally phosphorylated $\tau$ protein disproportionately occur in $A D$. However, the exact molecular mechanism of $A D$, as well as of other tauopathies, still eludes us. The famous amyloid cascade hypothesis [5] proposed that APP, normally cleaved by $\alpha$-secretase, is aberrantly processed by $\beta$ - and $\gamma$-secretases resulting in an imbalance between production and clearance of $A \beta$ peptide $[4,5]$. This hypothesis postulates that the production of amyloidogenic $A \beta$ peptides in the brain is neurotoxic, triggering neuronal atrophy that ultimately leads to dementia. However, it does not fully explain the etiology and pathogenesis of AD. This hypothesis suggested that any disturbance of signaling pathways in brain cells underlies the cognitive decline $[4,5]$. Several studies observed that the signal transduction pathways were disrupted, resulting in an imbalance of protein phosphorylation/dephosphorylation, hyperphosphorylation of $\tau$ proteins in neurons, and ultimately neurofibrillary degeneration [4-7].

Aging, environment, health status, and behavioral factors, such as smoking, alcohol addiction, cardiovascular diseases, hypertension, obesity, and diabetes, increase the risk of sporadic AD, as evidenced by epidemiological studies. Formulation of different hypotheses to describe the etiology of $A D$ identified several hypothetically pathogenic molecules. This knowledge raised the development of multiple drugs to target these mainstream pathogenic molecules, including the amyloid- $\beta$ peptide, $\tau$ protein, or acetylcholine $(A C h)[6,7]$. The FDA approved treatment with acetylcholinesterase (AchE) inhibitor for patients with mild to moderate AD. Memantine, an NMDA receptor antagonist, was used to treat patients with moderate to severe AD. These drugs can mildly relieve symptoms but not cure AD.

Great interest arose to develop drugs for curing $A D$. Secretase inhibitors and anti-A $\beta$ vaccines were developed based on the amyloid cascade hypothesis. The $\gamma$-secretase inhibitors, 
Semagacestat or Avagacestat, reduce $A \beta$ production in vitro and in experimental models. Anti-A $\beta$ vaccines increase $A \beta$ clearance [7]. Unfortunately, clinical trials revealed that amyloid based therapeutic approaches had limited efficacy. The trial with Semagacestat was discontinued for increased risk of skin cancer [8]. Thus, many studies focused on identifying new anti-AD therapeutic agents directed against other target molecules. Understanding the etiology of AD and the molecules involved could allow the identification of novel targets for therapeutic interventions.

Identifying the signal transduction pathways involved in $A D$ will provide great insight into the natural history of $A D$. Besides, it will offer promising perspectives about the therapeutic approaches to manage $A D$. The brain undergoes several morphological changes during the course of $A D$. Understanding the role and timing of action of the signaling pathways recruited during these changes might help elucidate the etiology and pathogenesis of the disease, paving the way for early diagnosis, prognosis refinement, and novel molecular therape utic strategies. Through this review, we explore the probable signal transduction pathways involved in AD pathogenesis.

\section{Signal Transduction in Alzheimer's Disease}

Growing evidence suggests that age-associated disorders, such as $A D$, characterized by a decline in cognitive and learning abilities, display disturbances in signal transduction. Although the etiology of $A D$ is still unknown, the primary pathological hallmarks associated with $A D$ are the accumulation of extracellular amyloid- $\beta(A \beta)$ plaques and intracellular neurofibrillary tangles of hyperphosphorylated $\tau$ protein $[8,9]$.

The imbalance in phosphorylation/dephosphorylation of selected proteins in degenerating neurons correlated with the abnormal activity of one or more signal transduction pathways, especially the complex signaling network that regulates calcium homeostasis. AD presents with altered neuronal $\mathrm{Ca}^{2+}$ homeostasis. Specifically, $\mathrm{Ca}^{2+}$ accumulates in affected neurons leading to functional impairment. As a result, there was a growing interest in the involvement of signal transduction pathways acting upon $\mathrm{Ca}^{2+}$ metabolism and regulation of phosphorylation of selected proteins. Presenilin (PS) is a major AD deterministic gene as its mutation contributes to over $90 \%$ of FAD cases. According to the genetic predisposition studies, PS affects cytoplasmic calcium $\left(\mathrm{Ca}^{2+}\right)$ homeostasis in neurons. The analysis of the role of PS pointed to $\mathrm{Ca}^{2+}$ dysregulation following mutation of the PS gene. The abnormalities in $\mathrm{Ca}^{2+}$ homeostasis occur before the formation of $A \beta$ plaques and neurofibrillary tangles in an $A D$ brain. Thus, a disruption in the level of cytoplasmic $\mathrm{Ca}^{2+}$ may be preliminary to the origin of $A D$ [10]. The metabolism of calcium is complex, with many macromolecules involved in several signal transduction pathways, offering potential targets for new therapeutic approaches.

A number of signal transduction pathways are implicated in the pathogenesis of $A D-W n t$ signaling pathway, mammalian target of rapamycin (mTOR) pathway, 5' adenosine monophosphate-activated protein kinase (AMPK) pathway, sirtuin pathway, phosphoinositide (PI) signal transduction pathway, and the pathways involving peroxisome proliferator-activated receptor $\gamma$ co-activator $1-\alpha$ (PGC-1 $\alpha)$ [11-13].

The world population is aging. It is a risk factor for neurodegenerative diseases. Therefore, many research efforts have been focused on identifying novel therapeutic regimens to delay the onset of age-related diseases.

There are multiple cellular and molecular events involved in neurodegenerative diseases, such 
as increased oxidative stress, impaired autophagy, misfolded proteins, impaired neuronal metabolism, and mitochondrial dysfunction.

Two main hypotheses lead the $A D$ research-the amyloid cascade hypothesis and the mitochondrial cascade hypothesis. The amyloid cascade hypothesis has long dominated the approach to $A D$ research. It hypothesizes that the accumulation of $A \beta$ peptides induces biochemical changes in the brain leading to the morphological and clinical features of $A D[8,9]$. This hypothesis was postulated after the identification of an APP mutation in a family with autosomal dominant amyloid angiopathy, dementia, and AD-typical histology features [8, 9]. Two other genes, PS1 and PS2, bearing mutations in autosomal dominant AD [6-9], contribute components of the $\gamma$-secretase complex, necessary to process APP. However, it was rapidly evident that sporadic AD patients did not have mutations in APP or PS genes. Also, the amyloid cascade hypothesis does not fully clarify the etiology and pathogenesis of AD. The molecular basis for the accumulation of neurotoxic forms of $A \beta$ remains unknown [7].

$A D$ is also characterized by reduced energy metabolism following alterations in the key enzymes involved in oxidative phosphorylation, associated with reduced neuronal expression of nuclear genes encoding subunits of the mitochondrial electron transport chain [13]. The more recent mitochondrial cascade hypothesis addresses the relationship between aging and $A D$ risk. This hypothesis incorporates the growing body of evidence for AD-related mitochondrial dysfunction and partially explains the biochemical abnormalities corresponding to $A D[9,14-16]$.

Many signal transduction pathways are fundamental to the maintenance of cellular functions, including synaptic structure and function, and mitochondrial integrity. The crosstalk between the main pathways and the interconnections with secondary cellular mechanisms are far from being elucidated. Regulation of $\mathrm{Ca}^{2+}$ metabolism is one of the convergence points of all the signal transduction pathways. $\mathrm{Ca}^{2+}$ imbalance may occur through impaired buffering capacity and modifications to the endoplasmic reticulum (ER) $\mathrm{Ca}^{2+}$ channels. This imbalance leads to neuronal apoptosis triggered by the calmodulin-dependent kinase activation, calpain activation, and the phosphoinositide signal transduction pathway.

\section{Wnt Signaling Pathways}

The evolutionarily conserved Wnt signaling pathways contribute to several aspects of cell survival, including migration, polarity, patterning, and determination in organogenesis during embryonic development (Figure 1). These comprise of different pathways, including the canonical pathway, the non-canonical planar cell polarity (PCP) pathway, and the non-canonical Wnt/calcium pathway. In humans, Wnt proteins are secreted glycoproteins belonging to a family of 19 proteins involved in complex signaling regulation, function, and biological output.

Studies have revealed that $\mathrm{Wnt}$ signaling is altered in AD. The levels of $\beta$-catenin were observed to decrease in $A D$ patients carrying presenilin-1-inherited mutations [17]. In vitro exposure to $A \beta$ inhibited the Wnt signaling in hippocampal neurons [18-20]. Similarly, apolipoprotein E (apoE), considered an $A D$ risk factor, inhibited the Wnt signaling [21-24]. Dickkopf-1 (Dkk1) is a Wnt antagonist induced by the $A \beta$ protein in hippocampal neurons [25]. Post-mortem brain samples from both $A D$ patients and experimental models revealed elevated Dkk1 levels [26]. It reversibly reduced the number of synaptic proteins and active pre-synaptic sites, inducing synaptic disassembly at pre- and postsynaptic sites $[24,25]$. Clusterin is considered a susceptibility factor 
for late-onset $A D$. It regulates $A \beta$ amyloid toxicity via Dkk1-driven induction of non-canonical Wnt/PCP-JNK-dependent signaling pathway, contributing to $\tau$ phosphorylation [26]. Plasma and cerebrospinal fluid from AD patients contained an elevated level of Dickkopf-3 (Dkk3), which is closely related to Dkk1 [27]. A genetic variant of the low-density lipoprotein receptor-related protein 6 (LRP6) favored AD progression.

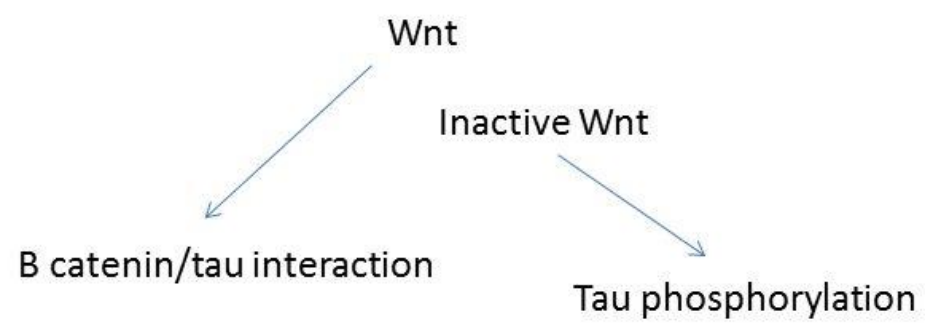

Figure 1 Wnt signaling.

Soluble $A \beta$ oligomers may be involved in abnormal synaptic communication, an early event occurring before plaque deposition, as well as in neuronal death [28]. The non-canonical Wnt5a ligand prevented the $A \beta$-induced decrease in amplitude of the excitatory postsynaptic potentials and the subsequent synaptic damage [29]. By participating in the Wnt/PCP-JNK-dependent pathway, Wnt5a also prevents the reduction of postsynaptic density-95 (PSD-95) clusters. Wnt5a activates the $\mathrm{Wnt} / \mathrm{Ca}^{2+}$ pathway and is involved in different cellular functions, such as regulation of $\mathrm{GABA}_{A}$ and NMDA receptors in neurons [30,31], development of dendritic spines [32], and protection of neuronal mitochondria from $A \beta$ oligomers [33]. In vivo activation of canonical and non-canonical Wnt signaling ameliorated the cognitive impairment in experimental animal models [34]. Thus, the alterations in the Wnt signaling pathway might be involved in the modulation of synaptic development and AD pathogenesis [35].

The activation of several signaling pathways, networking with the Wnt pathway, support the neuroprotective potential of the Wnt signaling cascade in AD. These include the pathways involving nicotinic and muscarinic ACh receptors, peroxisome proliferator-activated receptors (PPAR) $\alpha$ and $\gamma$, antioxidants, and anti-inflammatory molecules [36-38].

In post-mortem AD brains [39], the metabolism of acetylcholine was abnormal, with loss of cholinergic neurons in the basal forebrain. Thus, acetylcholine metabolism may be involved in the impairment of cognitive functions and behavioral disturbances observed in AD patients. The cortical impairment of cholinergic neurotransmission resulted in the alteration of the cholinergic system, including the reduced activity of acetylcholinesterase (AChE) and choline acetyltransferase [39]. The $A \beta-A C h E$ complexes are more neurotoxic than the aggregates of $A \beta$, depending on the AChE level [40]. The Wnt pathway also regulates the translocation of a subset of acetylcholine receptors (AChRs) to synapses [41]. In vivo analys is of the effects of mutations of Wnt ligand and related molecules suggested that synaptic plasticity is mediated, at least partly, by Wnt signaling.

Previous studies suggested that $A D$ pathogenesis might be related to free radical-induced oxidative stress $[42,43]$. Reducing oxidative stress by Wnt signaling activation after $A \beta$ accumulation might play a role in cognitive deficits. In vitro experiments demonstrated that $A \beta$ is neurotoxic and that inhibitors of catalase-A $\beta$ interactions play a protective role [43-45]. In vivo depletion of vitamin $E$, thus enhancing the oxidative state, results in increased $A \beta$ accumulation by 
inhibiting its clearance from the brain $[44,45]$.

A study on rat hippocampal neurons reported the proliferation of peroxisomes along with the corresponding increase in catalase. This could represent a protective factor from the neurotoxicity of $A \beta$ and might improve spatial memory, reduce $A \beta$ aggregates, reduce glial activation, decrease $\tau$ protein phosphorylation, and increase postsynaptic proteins and long-term potentiation (LTP) [45]. In murine primary hippocampal neurons, Wnt1 overexpression protected neurons against $A \beta$ mediated oxidative stress $[4,46]$. $A \beta$ toxicity can also induce the expression of glycogen synthase

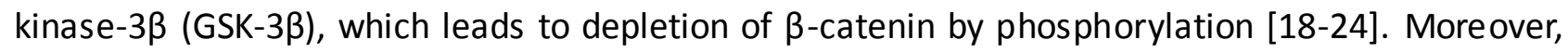
the increase in protein kinase $C$ (PKC) activity results in reduced production of $A \beta$ related to the Wnt pathway $[5,24]$. Overexpression of Disheveled (DSH) proteins, DSH-1 and DSH-2, inhibits $\tau$ phosphorylation by GSK-3 $\beta$, thus preventing the formation of neurofibrillary tangles and possibly conferring neuroprotection [47].

\section{4. mTOR Pathway}

The mammalian target of rapamycin (mTOR) pathway contributes to both intracellular and extracellular signaling regulating different cell activities, such as metabolism, growth, proliferation, and survival (Figure 2). The mTOR pathway is activated in numerous normal and pathological cellular processes, such as tumor growth, angiogenesis, insulin resistance, adipogenesis, and Tlymphocyte activation. The mTOR pathway is abnormal in human cancer and diabetes. Several mTOR inhibitors, such as rapamycin, are used in tumor treatments, organ transplantation, coronary restenosis, and rheumatoid arthritis. The mTOR protein is an evolutionarily conserved, $289 \mathrm{kDa}$, serine-threonine protein kinase, which belongs to the phosphoinositide 3-kinase (PI3K)related family. It nucleates at least two multi-protein complexes-mTOR complex 1 (mTORC1) and mTOR complex 2 (mTORC2).

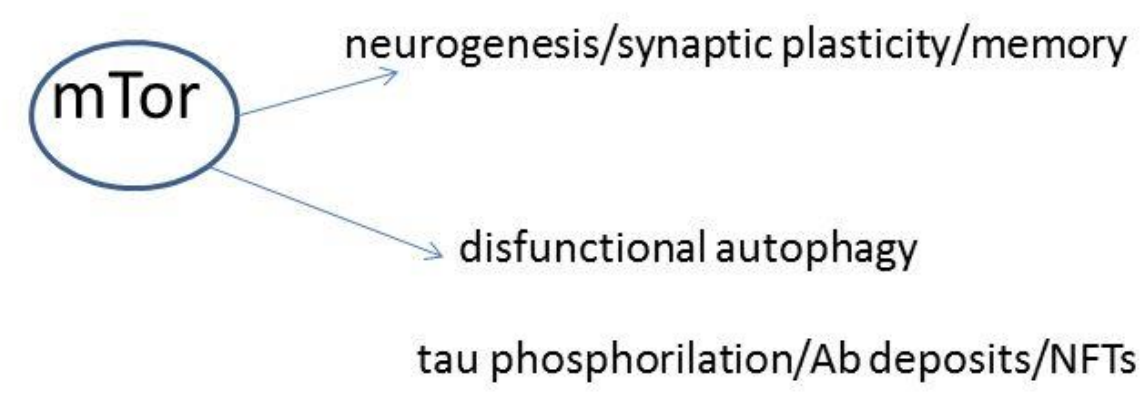

Figure 2 The mammalian target of rapamycin (mTOR) pathway.

The 5' AMP-activated protein kinase (AMPK) is a heterotrimeric protein kinase complex acting as a sensor of intracellular ATP levels and coupled to phosphorylation of the substrates in ATP synthesis [48]. The activity of AMPK is regulated in a complex way and possesses several downstream targets $[49,50]$. AMPK phosphorylates several sites on the transcription factor, forkhead box $\mathrm{O} 3$ (FOXO3), activating transcription of various genes, including those involved in the resistance to oxidative stress [51].

AMPK inhibits protein synthesis by phosphorylating Raptor and ULK1, a subunit of the mTORC1 
complex involved in autophagy $[52,53]$. In neurons, increased mTOR activity results in several stimuli, including BDNF, leptin, and $\mathrm{Ca}^{2+}$ influx, and contributes to the maintenance of synaptic plasticity by regulating protein synthesis required for the late-phase of long-term potentiation (LTP) [54]. Recent studies provided evidence that AMPK and mTOR are the main targets for deregulations in $A D$, thus emphasizing their roles in the development and progression of the disease $[55,56]$. However, it remains controversial.

In rat cortical neurons, AMPK activation inhibited phosphorylation of $\tau$ protein [57]. Other researchers confirmed that AMPK could phosphorylate $\tau$ protein at several sites, including Thr231 and Ser396/404, thus preventing it from binding to microtubules [58, 59]. Further studies in neurons suggested that AMPK activation represses amyloidogenesis [60].

AMPK activation decreases mTOR signaling, thus enhancing autophagy and lysosomal degradation of $A \beta$ [59]. Therapeutic doses of metformin, an anti-diabetic drug, could lead to activation of AMPK and upregulation of $\beta$-secretase (BACE1), a rate-limiting enzyme for $A \beta$ production, significantly increasing the generation of intracellular and extracellular $A \beta$ species [60].

\section{Sirtuin Pathway}

The silent mating-type information regulation proteins (sirtuins) comprise a class of proteins involved in metabolic regulation (Figure 3). They contribute to cellular processes, such as aging, transcription, apoptosis, inflammation, and stress resistance, as well as energy efficiency and regulation in low-calorie conditions. Sirtuins have mono-ADP-ribosyltransferase or deacylase activity, including deacetylase, desuccinylase, demalonylase, demyristoylase, and depalmitoylase activities.

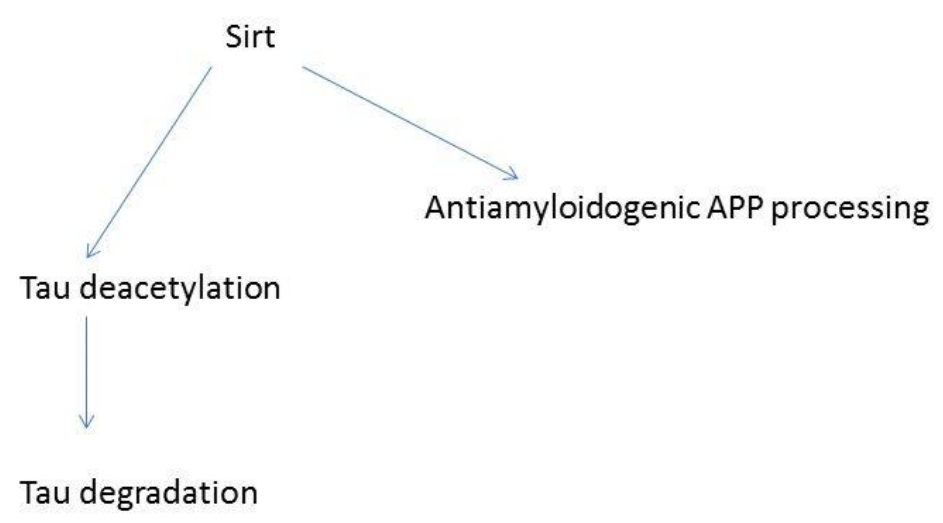

Figure 3 Sirtuins in metabolic regulation.

The protein structure of sirtuins is highly conserved in several species. Mammals produce seven sirtuins (SIRT1-7) selectively localized in different subcellular compartments. SIRT3, 4, and 5 are primarily mitochondrial; SIRT1, 6, and 7 are mainly nuclear; and SIRT2 is cytosolic [61]. Sirt3 regulates mitochondrial metabolism [62-64].

The regulation of mitochondrial biogenesis is complex. The activity of peroxisome proliferatoractivated receptor $\gamma$ coactivator $1 \alpha$ (PGC-1 $\alpha)$ [65] is strictly related to the deacetylation of SIRT1 [66]. PGC-1 $\alpha$ and its closely related isoform, PGC-1 $1 \beta$, are expressed in the brain, where they contribute to maintaining neuronal mitochondrial biogenesis [67]. Brain samples from AD patients 
revealed reduced PGC-1 $\alpha$ expression $[67,68]$.

In hippocampal AD tissues and M17 cells from APP mice, the levels of PGC-1 $\alpha$, nuclear respiratory factor (NRF) 1, and NRF2 significantly decreased compared to controls [12]. Thus, PGC$1 \alpha$ overexpression may protect from neurodegenerative diseases. In contrast, prolonged PGC $-1 \alpha$ overexpression was cytotoxic for dopaminergic neurons [68].

In the liver, SIRT1 deacetylates PGC-1 $\alpha$ at multiple lysine sites, thus enhancing its activity and inducing transcription of gluconeogenesis genes in the liver [69]. Therefore, the SIRT1/PGC-1 $\alpha$ pathway promotes adaptation to caloric restriction by regulating the genetic programs of the liver for gluconeogenesis and glycolysis. This pathway is probably a part of a more complex neural circuitry regulated in a nutrient-dependent fashion. SIRT1 functions in response to nutrientsensitive changes in basal NAD ${ }^{+}$levels [70]. Resveratrol, a SIRT1 activator, induces mitochondrial biogenesis and protects against metabolic decline.

Interestingly, resveratrol-mediated AMPK activation is dose-dependent. SIRT1 is the key effector of this interaction, playing an essential role in stimulating AMPK, and improving mitochondrial function in vitro and in vivo [70].

The SIRT1-PGC-1 $\alpha$ complex was implicated in AD. PGC-1 $\alpha$ modulates the transcription of $\beta$ secretase (BACE1) in eNOS-deficient mouse brains exposed to a high-fat diet [71].

Brain adaptations to endurance training included overexpression of PGC-1 $\alpha$ and SIRT1 mRNA, together with increased mitochondrial DNA content, increasing the mitochondrial mass [70].

$A \beta$ peptides can induce mitochondrial abnormalities. Experimental models demonstrated alterations in mitochondrial enzymes in the $A D$ brain. Decreased glucose metabolism precedes clinical diagnosis and is considered an early clinical indicator of mitochondrial failure in AD [72, 73]. $A D$ brains presented with a reduction in mitochondrial length, overexpression of dynamin-like protein 1 (DLP1), and downregulation of the optic atrophy protein 1 (OPA1) [74]. Moreover, the SIRT1-PGC-1 $\alpha$ axis and NRF regulate mitochondrial biogenesis.

Research efforts have been focused on preserving mitochondrial function in $A D$ by exploring different approaches, including strategies to reinforce the delivery of energy from the mitochondria [74] by preserving the mitochondrial mass, protecting from $\mathrm{Ca}^{+2}$ overload and membrane swelling, and ameliorating the redox status. These strategies comprise of dietary approaches with promising results. Dietary supplementation of melatonin and caffeine restored mitochondrial function in assays for respiratory rate, membrane potential, ROS production, and ATP level in the brains of the APP/PS1 in vivo models $[75,76]$. Micronized zeolite supplementation reduced mitochondrial reactive oxygen species (ROS), increased superoxide dismutase (SOD) levels, and attenuated $A \beta$ accumulation in the APP/PS1 mouse brain [77]. Salvia sahendica extracts prevented the $A \beta$-induced reduction in the levels of NRF1 and mitochondrial transcription factor $A$ (TFAM) [75]. The flavonoid, Apigenin, reduced the toxic effects of $A \beta$, restoring the redox balance acting upon intracellular glutathione levels. Additionally, it also enhanced the cellular SOD and glutathione peroxidase activities [78, 79]. In experimental models, nicotinamide ameliorated the cognitive performance concordant with normalizing mitochondrial dynamics and increased the expression of DLP1 in the cerebral cortex [79]. Selected polyphenols ameliorated membrane disruption caused by the $A \beta 42$ peptide and $\tau-441$ protein [80]. Besides the cited examples, there is an increasing body of evidence supporting the dietary approach. In this perspective, novel molecules, both natural and synthetic, were reported.

In experimental models, the increase in moderate exercise activity of the mitochondrial 
complexes I, III, and IV in the brain could prevent age-dependent mitochondrial decline [80]. Physical activity induces the regulation of brain mitochondrial redox balance, and chronically prolonged activity reduces apoptotic signaling in the AD brain [81].

The maintenance of intracellular NAD ${ }^{+}$levels in human brain cells may also be crucial for their viability under chronic oxidative stress and mitochondrial dysfunction through the promotion of oxidative phosphorylation (ATP production). NAD ${ }^{+}$is also closely associated with the DNA binding poly (ADP-ribose) polymerases (PARPs) [82-84]. Increased levels of PARP have been reported in the frontal and temporal cortex in AD brains. PARP participates in DNA repair and recovery of normal cellular function. Under abnormal conditions, PARP activation leads to increased $\mathrm{NAD}^{+}$turnover, reduced ATP synthesis, and cessation of energy-dependent functions followed by cell death [85-87]. $\mathrm{NAD}^{+}$treatment reduced PARP-induced astrocyte death [86]. NAD ${ }^{+}$may also prevent neuronal injury by enhancing sirtuin activities and/or improving energy metabolism [87].

\section{PI Pathway}

Neurons communicate and coordinate their activities using chemical signals, such as neurotransmitters, neuropeptides, and hormones. The phosphoinositide (PI) signaling pathway plays a central role in regulating different neurotransmitters and neuropeptides [88, 89] (Figure 4). The role of PI molecules is well understood. PI signal transduction acts upon $\mathrm{Ca}^{2+}$ metabolism $[88$, 89]. Growing evidence suggests that $A \beta$ affects $\mathrm{Ca}^{2+}$ signaling by recruiting PI-related molecules. The cellular prion protein (PrPC), coupled with mGluR5 bound to $A \beta$, increases the recruitment of molecules of the PI system [90, 91]. This dramatically raises $\mathrm{Ca}^{2+}$ levels from 2 to 3 folds. In the nervous tissue, $\mathrm{PI}$ signaling primarily regulates the $\mathrm{Ca}^{2+}$ levels.

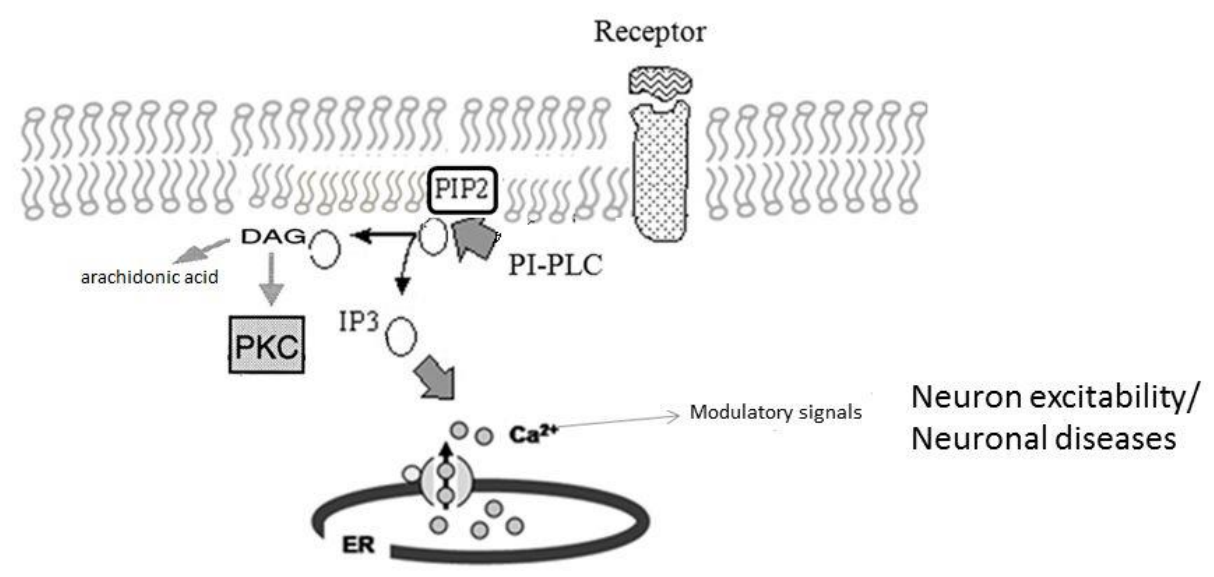

Figure 4 The PI pathway.

The PI signal transduction pathway contributes to different cell functions - hormone secretion, neurotransmission, cell growth, membrane trafficking, ion channel activity, cytoskeleton regulation, cell cycle control, apoptosis, and cell and tissue polarity. The role and timing of recruitment of the PI molecules during the changes in brain morphology in AD progression might provide clues to the pathogenesis of the disease, paving the way for prognosis refinement and novel molecular therapeutic strategies. 
PIs are phospholipids with hydroxylated inositol, a cyclohexane derivative, as the polar head group. The lipid moiety predominantly consists of 1-stearoyl-2-arachidonoyl fatty acid linked to the glycerol backbone $[92,93]$. The PI molecules are abundant in brain tissue and act as signal transducers through the plasma membrane $[92,93]$.

The PI signal transduction pathway comprises of seven differently phosphorylated lipids: phosphatidylinositide 3-phosphate (PI3P), PI4P, PI5P, phosphatidylinositol 4,5-bisphosphate (PIP2), PI $(3,4) P 2$, PI $(3,5) P 2$, and phosphatidylinositol 3,4,5-triphosphate or PIP3. Several PI-specific enzymes modulate the phosphorylation/dephosphorylation events producing the different PIPs. Kinases phosphorylate and phosphatases dephosphorylate the hydroxyl groups of inositol at different positions [92].

Also, the PI signaling pathway in the nervous system constitutes a network of structurallyrelated membrane phospholipids contributing to numerous cellular activities, including proteinmediated inter-organelle lipid transport [92-95]. This pathway is involved in the $\mathrm{Ca}^{2+}$ signaling cascade during the development of the nervous system, as well as in the maintenance of neural plasticity and synapse formation [92].

In the nervous system, as in many mammalian tissues, phosphatidylinositol is the most abundant of the PI molecules, followed by PI4P and PIP2. The remaining phosphoinositides are less abundant. Often, receptor-activated PI3-kinase (PI3K) pathways produce transient D3phosphorylated lipids [95]. Modifications in localization or concentration of PIs, and presence of PI molecules like PIP2 or PIP3, elicit different cellular responses, such as activation/silencing of gene expression, DNA replication, or chromatin degradation. PIP2 directly regulates different activities in the cell, such as cytoskeleton reorganization, cytokinesis, membrane dynamics, nuclear events, and channel activities [92, 93]. PIP2 level is crucial for cell homeostasis and function. It depends on the activity of converting enzymes, such as PI-specific phospholipase C (PLC) [91]. Notably, the synaptic dysfunction due to oligomeric assemblies of $A \beta$ depends upon the levels of PIP2. Incubation of primary cortical neurons with oligomeric A $\beta$ reduced the level of PIP2 [95].

Several enzymes regulate the metabolism of PI molecules, such as receptor-stimulated PLC and PI3K [92]. PIP2 directly regulates numerous cellular functions [92]. Strict regulation of its levels by converting enzymes is crucial for homeostasis. Alterations in the level of PIP2 may result in critical events, such as synaptic dysfunction following the oligomeric assembly of A $\beta$ [95]. PLC enzymes regulate different events, activated by many molecules, at several levels in the control hierarchy. The PLC family of enzymes contributes to the spatiotemporal regulation of PIP2 levels [92].

PLC-mediated hydrolysis of PIP2 generates two more signaling molecules, diacylglycerol (DAG) and inositol triphosphate (IP3). IP3 directly induces an increase of intracellular $\mathrm{Ca}^{2+}$. After diffusing to the cytoplasm, IP3 induces $\mathrm{Ca}^{2+}$-release from the endoplasmic reticulum (ER) by binding to IP3gated $\mathrm{Ca}^{2+}$-release channels located in the ER membrane [91]. DAG is cleaved, releasing arachidonic acid. It can also activate the serine/threonine $\mathrm{Ca}^{2+}$-dependent protein kinase $\mathrm{C}$ (PKC) family of enzymes. This increase of $\mathrm{Ca}^{2+}$ moves PKC to translocate from cytoplasm to the cytoplasmic face of the plasma membrane [91]. Activated PKC enzymes phosphorylate specific serine or threonine residues on target proteins [91, 96].

PLC isoforms are classified into six subfamilies sharing sequence similarity, domain organization, and general regulatory mechanism [91]. Some subfamilies comprise of different is oforms $-\beta(1-4)$, $\gamma(1,2), \delta(1,3,4), \varepsilon(1), \zeta(1)$, and $\eta(1,2)[91,96]$-sometimes presenting different splicing variants. The PLC family participates in different mechanisms and interactions depending on the specific 
structure of each subfamily. The PI family overall contributes to membrane recruitment, interaction with small GTPases from Ras and Rho families, interaction with heterotrimeric G protein subunits, and recognition of specific sites in tyrosine kinase receptors [97].

The distribution of PLC enzymes is strictly tissue-specific. Besides the above characteristics, each isoform has a specific mechanism of recruitment as well as highly specific domains in the enzyme structure that may influence its function and its ability to modulate responses in the pathway [91]. The hypothesis that each PLC isoform may bear a specific role was corroborated by their involvement in the development and diseases of the nervous system [95].

PLC $\beta 1$ is considered a molecular convergence point of several neurotransmitter pathways implicated in schizoaffective disorders and epileptic encephalopathy [97-105]. The human gene that codes for PLC $\beta 3$ (PLCB3; OMIM *600230) maps to a genomic region associated with neurodegenerative diseases [106]. PLC $\gamma 1$ was expressed by embryonic radial glia during fetal brain development [107]. It contributed to neocortex formation through a TrkB-Shc/PLC $\gamma$-mediated control of neuronal migration [108]. Also, PLC $\gamma 1$ was linked to schizoaffective disorders [108]. PLC $\varepsilon$ isoform was involved in neuronal lineage differentiation, probably in intracellular signaling from receptors for growth factors and various neurotrophic factors during neural development [109]. Enzymes belonging to the PLC $\eta$ subfamily modulated and amplified $\mathrm{Ca}^{2+}$ signals in neuronal regions of the brain associated with learning and memory [110]. PLCH2 (OMIM *612836), the gene that codes for PLC $\eta 2$, was implicated in mental retardation. The post-mortem brain samples of individuals who committed suicide displayed an abnormal panel of expression of PLC is oforms.

Also, the PLC enzymes in glia might be involved in AD pathogenesis. Recent reports suggested that $A D$ injury is not exclusive to neurons. Misfolded or aggregated proteins bind to pattern recognition receptors on microglia and astroglia and release inflammatory mediators. These mediators might contribute to disease progression and worsen the prognosis [111]. PLC enzymes were implicated in the inflammatory activation of glia [111-113].

Finally, several signal transduction pathways mediate abnormal phosphorylation patterns in tauopathy, including the PLC enzymes. Different combinations of PKCs, activated by PLC enzymes, may hyperphosphorylate the $\tau$ protein [114]. Widening the pathway of PLC over PIP2, PKC enzymes affect the synaptic remodeling, crucial for learning and memory, including acquisition, consolidation, and reconsolidation. Insulin activates the PKC signaling pathway via PLC $\gamma$ isoforms, Erk 1/2 MAP kinase, and Src stimulation. Evidence also suggested that PLC-mediated PKC activation occurs during neuronal repair processes [115].

We could explain the central role of PLCs in AD in relation to $\mathrm{Ca}^{2+}$ metabolism. During aging, the cholesterol/phospholipid ratio undergoes the most remarkable change in the plasma membrane $[115,116]$. This could be a result of abnormal microviscosity of cell membranes [117, 118], with progressive reduction of fluidity. In the aging rat brain, neuronal/glial plasma membrane components showed differences in the turnover of phospholipids [119, 120], increased methylation of phosphatidylethanolamine [120], and decreased synthesis of phosphatidylethanolamine and phosphatidylcholine [121]. Similarly, in humans, there was a rapid loss of membrane lipids after 90 years of age [122], and decreased lipid-myoinositol concentrations in the 39 areas of the cortex (Brodmann's area) [123]. Additionally, the membranes of cytoplasmic organelles of aging cells displayed similar biochemical changes [124]. The modified composition of brain cell membranes occurring in AD probably results in functional changes in their biophysical properties [124]. 
During aging, there was an increase in the levels of phosphomonoesters, due to increased PLC activity, and phosphodiesters [125]. The level of phosphomonoesters inversely correlated with the number of senile plaques; whereas, the level of phosphodiesters directly correlated with the plaques [126]. In $A D$, the levels of phosphomonoesters in neocortex and allocortex were found to elevate early, followed by elevation of phosphodiesters in cortex and subcortex and subsequent cellular degeneration and death [127]. In the anterior region of the temporal cortex (TC) of AD brains, PI levels were significantly lower compared to controls [127]. PIP and PIP2 levels also decreased in $A D$. However, the long and variable delays in post-mortem are important limitations of the studies, as PI molecules degrade rapidly $[128,129]$. Many reports indicated a decline in the functional integrity of receptor-mediated signal transduction mechanisms, particularly in the $G$ protein-linked signal transduction pathways.

The $\mathrm{G}$ protein-stimulated adenylate cyclase activity was impaired in the frontal cortex $(F C)$ of $A D$ brains. Accumulation of PLC in selected brain regions, such as the TC and hippocampus, contributed to the formation of paired helical filaments [130]. Again, the post-mortem evaluation of PLC is difficult for artifacts due to receptor-mediated breakdown of PI [131].

The cytoplasm fractions displayed the greatest decline in PI kinase activity in the cortex of AD brain, in contrast to its activity in integral membrane protein fractions [132-136]. Neurofibrillary tangles partially consist of incorrectly metabolized or degraded cytoskeleton components. In the cortex of AD brains, type 1 PI kinase was affected, which is involved in regulating the turnover of cytoskeletal proteins [132].

In the TC and hippocampus of AD brains, the number of IP3 binding sites for $\mathrm{Ca}^{2+}{ }_{\text {-release }}$ reduced by $50-70 \%$ [136], and $\mathrm{Na}^{+} / \mathrm{Ca}^{2+}$ exchange activity increased. This indicates a condition of sufferance or degeneration in the neurons [137]. $\mathrm{Ca}^{2+}$ homeostasis related to $\mathrm{PI}$ metabolism might be involved in neurofibrillary degeneration through the activation of PKCs. A $\beta$ protein is a physiological substrate of PKC [138]. PKC immunoreactivity was detected in mature plaques [139, 140] and cytoskeleton-associated PKC subtype/ $3 I I$, which could be an early biochemical marker of $A D[141,142]$. In the FC of AD brains, the level of PKC and the in vitro phosphorylation of its $86 \mathrm{kDa}$ substrate decreased and changed its location from the particulate pool to the soluble cytosolic pool [143]. A possible explanation is that PKC acts upon protein tyrosine phosphorylation [144, 145]. In the FC from AD brains, the protein tyrosine kinase (PTK) activity decreased by two-fold in the particulate fraction; whereas, its activity did not change in the cytosolic fraction [146].

The number of metabotropic glutamate receptors (mGluRs) decreased in the cerebral cortex in early $A D$ changes, not involving FC. However, it correlated with ne uropathological changes in AD, with the highest values reaching in isocortical stages, which was associated with a decrease in the expression levels. $A \beta$ bound to mGluR5 was found to be coupled with Cellular Prion Protein ( $\operatorname{PrPC})$. This induced activation of $\mathrm{PI}$ signaling, increased $\mathrm{Ca}^{2+}$ and led to memory loss soon after the $A \beta$ plaques were formed [145]. In AD, the expression levels of PLC $\beta 1$ is oform, an effector of group I mGluRs, were associated with reduced GTP- and I-glutamate-stimulated PLC activity. In the FC of AD brain, the mGluRs/PLC system was downregulated and desensitized. This deregulation strictly related to the progression of $A D$ changes in the neocortex [145].

Oxidative stress-induction by administering aluminum into in vivo models significantly increased the level of PLC 81 , with no effects on the levels of PLC $\beta 1$ or PLC $\gamma 1$. The total PLC activity in aluminum-treated rat brains was higher than control brains, following the induction of oxidative stress [146-150]. PLC 81, which abnormally accumulates in neurofibrillary tangles, was 
concentrated in the paired helical filament (PHF)-rich fraction of AD brains. Abnormal deposition of PLC $\delta 1$ preceded the accumulation of fibrillary deposits, suggesting that PLC $\delta 1$ increases before the formation of PHF $[145,146]$. Moreover, PLC $\delta 1$ mainly localized within the neurons on the amorphous granular components of neurofibrillary tangles and abnormal filaments. This suggests that PLC $\delta 1$ might be involved in the formation of neuronal filamentous inclusions $[145,146]$. The human apolipoprotein E gene (APOE; OMIM +107741) has different alleles. PLC $\delta 1$ activity decreased in the platelets of patients homozygous for the APOE3 allele. PLC $\delta 1$ activity did not change in patients with an APOE4 allele [145-147].

PLC $\gamma$ is oforms increased in the cytosol fraction than in the membrane fraction in several control brain regions. Also, they increased in the membrane of the hippocampus. These isoforms also increased in the membrane and the cytosolic fractions of the superior and middle temporal gyri. These suggest that PLC $\gamma$ subfamily might be involved in the pathogenesis or progression of AD or both [148].

Many studies demonstrated that different PI signal transduction pathways are involved in the nervous development, in the maintenance of neural plasticity, and in the formation of the synapse. Numerous molecules act and interact in an extremely complex network and different spatiotemporal frames, influencing neural development.

Many reports, although controversial, suggested that isoforms of the PLC family might be involved in the pathogenesis of $A D$; though, many claims remain to be verified. The relationship between $A \beta$-induced $\mathrm{Ca}^{2+}$ signaling is strictly related to memory loss [13-15]. Moreover, PLCs might be involved in the reduction of the fluidity of the cell membranes, which invariably occurs with increasing age, and in neurodegenerative disorders.

\section{Conclusions}

Many pieces of evidence indicate that several signal transduction pathways alter neurotransmission. Direct and indirect data suggest the involvement of these pathways in the progression and initiation of Alzheimer's disease. However, we still lack clarity concerning nature, the meaning, and the time of recruitment of specific signaling molecules.

Recent advances provide insight into the delineation of the metabolic pathways acting in the nervous system, although the developmental period of recruitment is not entirely clear. The complex interplay of the signaling molecules during the neuronal metabolism needs to be explored further, concerning the embryonic age, development, and aging.

We need to identify the molecules and events that regulate the multiple activities of the nervous system. This includes knowledge of the role and timing of action of the signaling pathways recruited for the changes in brain morphology in the progression of $A D$. These will help elucidate the etiology and pathogenesis of $A D$, paving the way for novel molecular therapeutic strategies.

\section{Author Contributions}

The author did all the research work of this study.

\section{Competing Interests}

The author has declared that no competing interests exist. 


\section{References}

1. Selkoe DJ, Mandelkow E, Holtzman D. Deciphering Alzheimer disease. CSH Perspect Med. 2012; 2: a011460.

2. Serrano-Pozo A, Frosch MP, Masliah E, Hyman BT. Neuropathological alterations in Alzheimer disease. CSH Perspect Med. 2011; 1: a006189.

3. Swerdlow RH. Pathogenesis of Alzheimer's disease. Clin Interv Aging. 2007; 2: 347-359.

4. Goate A, Chartier-Harlin MC, Mullan M, Brown J, Crawford F, Fidani L, et al. Segregation of a missense mutation in the amyloid precursor protein gene with familial Alzheimer's disease. Nature. 1991; 349: 704-706.

5. Sherrington R, Rogaev El, Liang $Y$, Rogaeva EA, Levesque G, Ikeda $M$, et al. Cloning of a gene bearing missense mutations in early-onset familial Alzheimer's disease. Nature. 1995; 375: 754-760.

6. Sorbi S, Bird ED, Blass JP. Decreased pyruvate dehydrogenase complex activity in Huntington and Alzheimer brain. Ann Neurol. 1983; 13: 72-78.

7. Hardy JA, Higgins GA. Alzheimer's disease: The amyloid cascade hypothesis. Science. 1992; 256: 184-185.

8. Caricasole A, Copani A, Caruso A, Caraci F, lacovelli L, Sortino MA, et al. The Wnt pathway, cell-cycle activation and beta-amyloid: Novel therapeutic strategies in Alzheimer's disease? Trends Pharmacol Sci. 2003; 24: 233-238.

9. Hirai K, Aliev G, Nunomura A, Fujioka H, Russell RL, Atwood CS, et al. Mitochondrial abnormalities in Alzheimer's disease. J Neurosci. 2001; 21: 3017-3023.

10. Cai Z, Li B, Li K, Zhao B. Down-regulation of amyloid-beta through AMPK activation by inhibitors of GSK-3beta in SH-SY5Y and SH-SY5Y-AbetaPP695 cells. J Alzheimers Dis. 2012; 29: 89-98.

11. Kruman I, Guo Q, Mattson MP. Calcium and reactive oxygen species mediate staurosporineinduced mitochondrial dysfunction and apoptosis in PC12 cells. J Neurosci Res. 1998; 51: 293308.

12. Wareski P, Vaarmann A, Choubey V, Safiulina D, Liiv J, Kuum M, et al. PGC-1 $\alpha$ and PGC-1 $\beta$ regulate mitochondrial density in neurons. J Biol Chem. 2009; 284: 21379-21385.

13. Mattson M. Pathways towards and away from Alzheimer's disease. Nature. 2004; 430: 631639.

14. Chandrasekaran K, Giordano T, Brady DR, Stoll J, Martin LJ, Rapoport SI. Impairment in mitochondrial cytochrome oxidase gene expression in Alzheimer disease. Brain Res Mol Brain Res. 1994; 24: 336-340.

15. Gu XM, Huang HC, Jiang ZF. Mitochondrial dysfunction and cellular metabolic deficiency in Alzheimer's disease. Neurosci Bull. 2012; 28: 631-640.

16. Silva DF, Selfridge JE, Lu J, Lezi E, Cardoso SM, Swerdlow RH. Mitochondrial abnormalities in Alzheimer's disease: Possible targets for therape utic intervention. Adv Pharmacol. 2012; 64: 83-126.

17. Zhang Z, Hartmann H, Do VM, Abramowski D, Sturchler-Pierrat C, Staufenbiel M, et al. Destabilization of beta-catenin by mutations in presenilin-1 potentiates neuronal apoptosis. Nature. 1998; 395: 698-702. 
18. Nusse R, Varmus H. Three decades of Wnts: A personal perspective on how a scientific field developed. EMBO J. 2012; 31: 2670-2682.

19. Clevers H, Nusse R. Wnt/ $\beta$-catenin signaling and disease. Cell. 2012; 149: 1192-1205.

20. Angers S, Moon RT. Proximal events in Wnt signal transduction. Nat Rev Mol Cell Biol. 2009; 10: 468-477.

21. Ciani L, Salinas P. WNTs in the vertebrate nervous system nervous system: From patte rning to neuronal connectivity. Nat Rev Neurosci. 2005; 6: 351-362.

22. Rosso SB, Inestrosa NC. WNT signaling in neuronal maturation and synaptogenesis. Front Cell Neurosci. 2013, 7: 103.

23. De Ferrari GV, Chacon MA, Barria MI, Garrido JL, Godoy JA, Olivares G, et al. Activation of Wnt signaling rescues neurodegeneration and behavioral impairments induced by betaamyloid fibrils. Mol Psychiat. 2003; 8: 195-208.

24. Alvarez A, Godoy JA, Mullendorff K, Olivares GH, Bronfman M, Inestrosa NC. Wnt-3a overcomes beta-amyloid toxicity in rat hippocampal neurons. Exp Cell Res. 2004; 297: 186196.

25. Caricasole A, Copani A, Caraci F, Aronica E, Rozemuller AJ, Caruso A, et al. Induction of Dickkopf-1, a negative modulator of the Wnt pathway, is associated with neuronal degeneration in Alzheimer's brain. J Neurosci. 2004; 24: 6021-6027.

26. Rosi MC, Luccarini I, Grossi C, Fiorentini A, Spillantini MG, Prisco A, et al. Increased Dickkopf-1 expression in transgenic mouse models of neurodegenerative disease. J Neurochem. 2010; 112: 1539-1551.

27. Purro SA, Dickins EM, Salinas PC. The secreted Wht antagonist Dickkopf-1 is required for amyloid-beta-mediated synaptic loss. J Neurosci. 2012; 32: 3492-3498.

28. Purro SA, Galli S, Salinas PC. Dysfunction of Wnt signaling and synaptic disassembly in neurodegenerative diseases. J Mol Cell Biol. 2014; 6: 75-80.

29. Killick R, Ribe E, Ribe EM, Al-Shawi R, Malik B, Hooper C, et al. Clusterin regulates $\beta$-amyloid toxicity via Dickkopf-1-driven induction of the Wnt-PCP-JNK pathway. Mol Psychiatry. 2014; 19: 88-98.

30. Cerpa W, Farias GG, Godoy JA, Fuenzalida M, Bonansco C, Inestrosa NC. Wnt-5a occludes Abeta oligomer-induced depression of glutamatergic transmission in hippocampal neurons. Mol Neurodegeneration. 2010; 5: 3.

31. Muñoz FJ, Godoy JA, Cerpa W, Poblete IM, Huidobro-Toro JP, Inestrosa NC. Wnt-5a increases NO and modulates NMDA receptor in rat hippocampal neurons. Biochem Biophys Res Commun. 2014; 444: 189-194.

32. Coutiño L, Godoy JA, Couve A, Fuenzalida M, Inestrosa NC. Wnt-5a modulates recycling of functional GABAA receptors on hippocampal neurons. J Neurosci. 2010; 30: 8411-8420.

33. Farias GG, Alfaro IE, Cerpa W, Grabowski CP, Godoy JA, Bonansco C. Wnt-5a/JNK signaling promotes the clustering of PSD-95 in hippocampal neurons. J Biol Chem. 2009; 284: 1585715866.

34. Varela-Nallar L, Alfaro IE, Serrano FG, Parodi J, Inestrosa NC. Wingless-type family member $5 \mathrm{~A}(\mathrm{Wnt}-5 \mathrm{a})$ stimulates synaptic differentiation and function of glutamatergic synapses. Proc Natl Acad Sci USA. 2010; 107: 21164-21169. 
35. Vargas J, Fuenzalida M, Inestrosa NC. In vivo activation of Wnt signaling pathway enhances cognitive function of adult mice and reverses cognitive deficits in an Alzheimer's disease model. J Neurosci. 2014; 34: 2191-2202.

36. Inestrosa NC, Varela-Nallar L. Wnt signaling in the nervous system and in Alzheimer's disease. J Mol Cell Biol. 2014; 6: 64-74.

37. Inestrosa NC, Toledo EM. The role of Wnt signaling in neuronal dysfunction in Alzheimer's disease. Mol Neurodegeneration. 2008; 3: 9.

38. Inestrosa NC, Arenas E. Emerging roles of Wnts in the adult nervous system. Nat Rev Neurosci. 2010; 11: 77-86.

39. Dumas JA, Newhouse PA. The cholinergic hypothesis of cognitive aging revisited again: cholinergic functional compensation. Pharmacol Biochem Behav. 2011; 99: 254-261.

40. Munoz FJ, Inestrosa NC. Neurotoxicity of acetylcholinesterase amyloid beta-peptide aggregates is dependent on the type of Abeta peptide and the AChE concentration present in the complexes. FEBS letters. 1999; 450: 205-209.

41. Jensen M, Hoerndli FJ, Brockie PJ, Wang R, Johnson E, Maxfield D, et al. Wnt signaling regulates acetylcholine receptor translocation and synaptic plasticity in the adult nervous system. Cell. 2012; 149: 173-187.

42. Jensen M, Brockie PJ, Maricq AV. Wnt signaling regulates experience-dependent synaptic plasticity in the adult nervous system. Cell Cycle. 2012, 11: 2585-2586.

43. Lee HP, Zhu X, Casadesus G, Castellani RJ, Nunomura A, Smith MA, et al. Antioxidant approaches for the treatment of Alzheimer's disease. Expert Rev Neurother. 2010; 10: 12011208.

44. Habib LK, Lee MT, Yang J. Inhibitors of catalase-amyloid interactions protect cells from betaamyloid-induced oxidative stress and toxicity. J Biol Chem. 2010; 285: 38933-38943.

45. Quintanilla RA, Munoz FJ, Metcalfe MJ, Hitschfeld M, Olivares G, Godoy JA, et al. Trolox and 17 beta-estradiol protect against amyloid beta-peptide neurotoxicity by a mechanism that involves modulation of the Wnt signaling pathway. J Biol Chem. 2005; 280: 11615-11625.

46. Inestrosa NC, Carvajal FJ, Zolezzi JM, Tapia-Rojas C, Serrano F, Karmelic D, et al. Peroxisome proliferators reduce spatial memory impairment, synaptic failure, and neurodegeneration in brains of a double transgenic mice model of Alzheimer's disease. J Alzheimers Dis. 2013; 33: 941-959.

47. Miyaoka T, Seno H, Ishino H. Increased expression of Wnt-1 in schizophrenic brains. Schizophr Res. 1999; 38: 1-6.

48. Wagner U, Brownlees J, Irving NG, Lucas FR, Salinas PC, Miller CC. Overexpression of the mouse dishevelled-1 protein inhibits GSK-3beta-mediated phosphorylation of tau in transfected mammalian cells. Febs Lett. 1997; 411: 369-372.

49. Ruderman NB, Carling D, Prentki M, Cacicedo JM. AMPK, insulin resistance, and the metabolic syndrome. J Clin Invest. 2013; 123: 2764-2772.

50. Hardie DG, Ross FA, Hawley SA. AMP-activated protein kinase: A target for drugs both ancient and modern. Chem Biol. 2012; 19: 1222-1236.

51. Jager S, Handschin C, St-Pierre J, Spiegelman BM. AMP-activated protein kinase (AMPK) action in skeletal muscle via direct phosphorylation of PGC-1 $\alpha$. Proc Natl Acad Sci USA. 2007; 104: 12017-12022. 
52. Greer EL, Oskoui PR, Banko MR, Maniar JM, Gygi MP, Gygi SP, et al. The energy sensor AMPactivated protein kinase directly regulates the mammalian FOXO3 transcription factor. J Biol Chem. 2007; 282: 30107-30119.

53. Egan DF, Shackelford DB, Mihaylova MM, Gelino S, Kohnz RA, Mair W, et al. Phosphorylation of ULK1 (hATG1) by AMP-activated protein kinase connects energy sensing to mitophagy. Science. 2011; 331: 456-461.

54. Alers S, Loffler AS, Wesselborg S, Stork B. Role of AMPK-mTOR-Ulk1/2 in the regulation of autophagy: Cross talk, shortcuts, and feedbacks. Mol Cell Biol. 2012; 32: 2-11.

55. Garelick MG, Kennedy BK. TOR on the brain. Exp Gerontol. 2011; 46: 155-163.

56. Yates SC, Zafar A, Hubbard P, Nagy S, Durant S, Bicknell R, et al. Dysfunction of the mTOR pathway is a risk factor for Alzheimer's disease. Acta Neuropathol Commun. 2013; 1: 3.

57. Greco SJ, Sarkar S, Johnston JM, Tezapsidis N. Leptin regulates tau phosphorylation and amyloid through AMPK in neuronal cells. Biochem Biophys Res Commun. 2009; 380: 98-104.

58. Thornton C, Bright NJ, Sastre M, Muckett PJ, Carling D. AMP-activated protein kinase (AMPK) is a tau kinase, activated in response to amyloid beta-peptide exposure. Biochem J. 2011; 434: 503-512.

59. Vingtdeux V, Davies P, Dickson DW, Marambaud P. AMPK is abnormally activated in tangleand pre-tangle-bearing neurons in Alzheimer's disease and other tauopathies. Acta Neuropathol. 2011; 121: 337-349.

60. Vingtdeux V, Giliberto L, Zhao H, Chandakkar P, Wu Q, Simon JE, et al. AMP-activated protein kinase signaling activation by resveratrol modulates amyloid-beta peptide metabolism. J Biol Chem. 2010; 285: 9100-9113.

61. Cai Z, Yan LJ, Li K, Quazi SH, Zhao B. Roles of AMP-activated protein kinase in Alzheimer's disease. Neuromolecular Med. 2012; 14: 1-14.

62. Godoy JA, Zolezzi JM, Braidy N, Inestrosa NC. Role of Sirt1 during the ageing process: Relevance to protection of synapses in the brain. Mol Neurobiol. 2014; 50: 744-756.

63. Rose G, Dato S, Altomare K, Bellizzi D, Garasto S, Greco V, et al. Variability of the SIRT3 gene, human silent information regulator Sir2 homologue, and survivorship in the elderly. Exp Gerontol. 2003; 38: 1065-1070.

64. Lombard DB, Alt FW, Cheng HL, Bunkenborg J, Streeper RS, Mostoslavsky R, et al. Mammalian Sir2 homolog SIRT3 regulates global mitochondrial lysine acetylation. Mol Cell Biol. 2007; 27: 8807-8814.

65. Schlicker C, Gertz M, Papatheodorou P, Kachholz B, Becker CF, Steegborn C. Substrates and regulation mechanisms for the human mitochondrial sirtuins Sirt3 and Sirt5. J Mol Biol. 2008; 382: 790-801.

66. Fernandez-Marcos PJ, Auwerx J. Regulation of PGC-1 $\alpha$, a nodal regulator of mitochondrial biogenesis. Am J Clin Nutr. 2011; 93: 884S-890S.

67. Katsouri L, Parr C, Bogdanovic N, Willem M, Sastre M. PPARgamma co-activator-1alpha (PGC1alpha) reduces amyloid-beta generation through a PPARgamma-dependent mechanism. J Alzheimers Dis. 2011; 25: 151-162.

68. Nemoto S, Fergusson MM, Finkel T. SIRT1 functionally interacts with the metabolic regulator and transcriptional coactivator PGC-1 $\alpha$. J Biol Chem. 2005; 280: 16456-16460. 
69. Jones AW, Yao Z, Vicencio JM, Karkucinska-Wieckowska A, Szabadkai G. PGC-1 family coactivators and cell fate: Roles in cancer, neurodegeneration, cardiovascular disease and retrograde mitochondria-nucleus signalling. Mitochondrion. 2012; 12: 86-99.

70. Sack MN, Finkel T. Mitochondrial metabolism, sirtuins, and aging. CSH Perspect Biol. 2012; 4: a013102.

71. Price NL, Gomes AP, Ling AJ, Duarte FV, Martin-Montalvo A, North BJ, et al. SIRT1 is required for AMPK activation and the beneficial effects of resveratrol on mitochondrial function. Cell Metabol. 2012; 15: 675-690.

72. Montinaro M, Uberti D, Maccarinelli G, Bonini SA, Ferrari-Toninelli G, Memo M. Dietary zeolite supplementation reduces oxidative damage and plaque generation in the brain of an Alzheimer's disease mouse model. Life Sci. 2013; 92: 903-910.

73. Swerdlow RH, Khan SM. A "mitochondrial cascade hypothesis" for sporadic Alzheimer's disease. Med Hypotheses. 2004; 63: 8-20.

74. Piaceri I, Rinnoci V, Bagnoli S, Failli Y, Sorbi S. Mitochondria and Alzheimer's disease. J Neurol Sci. 2012; 322: 31-34.

75. Garcia-Escudero V, Martin-Maestro P, Perry G, Avila J. Deconstructing mitochondrial dysfunction in Alzheimer disease. Oxid Med Cell Longev. 2013; 2013: 162152.

76. Foolad F, Khodagholi F. Dietary supplementation with Salvia sahendica attenuates acetylcholinesterase activity and increases mitochondrial transcription factor $A$ and antioxidant proteins in the hippocampus of amyloid beta-injected rats. J Pharm Pharmacol. 2013; 65: 1555-1562.

77. Wei L, Yang H, Xie Z, Yang S, Yang H, Zhao C, et al. A butyrolactone derivative 3BDO alleviates memory deficits and reduces amyloid-beta deposition in an AbetaPP/PS1 transgenic mouse model. J Alzheimers Dis. 2012; 30: 531-543.

78. Zhao L, Wang JL, Wang YR, Fa XZ. Apigenin attenuates copper-mediated beta-amyloid neurotoxicity through antioxidation, mitochondrion protection and MAPK signal inactivation in an AD cell model. Brain Res. 2013; 1492: 33-45.

79. Marques-Aleixo I, Oliveira PJ, Moreira PI, Magalhaes J, Ascensao A. Physical exercise as a possible strategy for brain protection: Evidence from mitochondrial-mediated mechanisms. Prog Neurobiol. 2012; 99: 149-162.

80. Dragicevic N, Delic V, Cao C, Copes N, Lin X, Mamcarz M, et al. Caffeine increases mitochondrial function and blocks melatonin signaling to mitochondria in Alzheimer's mice and cells. Neuropharmacology. 2012; 63: 1368-1379.

81. Steiner JL, Murphy EA, McClellan JL, Carmichael MD, Davis JM. Exercise training increases mitochondrial biogenesis in the brain. J Appl Physiol. 2011; 111: 1066-1071.

82. Camilleri A, Zarb C, Caruana M, Ostermeier U, Ghio S, Hogen T, et al. Mitochondrial membrane permeabilisation by amyloid aggregates and protection by polyphenols. Biochim Biophys Acta. 1828; 2013: 2532-2543.

83. Massudi H, Grant R, Braidy N, Guest J, Farnsworth B, Guillemin GJ. Age-associated changes in oxidative stress and NAD + metabolism in human tissue. Plos One. 2012; 7: e42357.

84. Massudi H, Grant R, Guillemin GJ, Braidy N. NAD + metabolism and oxidative stress: The golden nucleotide on a crown of thorns. Redox Rep. 2012; 17: 28-46.

85. di Lisa F, Ziegler M. Pathophysiological relevance of mitochondria in NAD + meta bolism. FEBS Lett. 2001; 492: 4-8. 
86. Wang $H$, Schimoji M, Yu SW, Dawson TM, Dawson VL. Apoptosis inducing factor and PARP mediated injury in the MPTP mouse model of Parkinson's disease. Ann N Y Acad Sci. 2003; 991: 132-139.

87. Meyer R, Meyer-Ficca M, Jacobsen E, Jacobsen M. Enzymes in poly(ADP-Ribose) metabolism. Poly(ADP-Ribosyl)ation. Edited by: Burkle A. New York: Springer-Landes Bioscience; 2006.

88. Alano CC, Ying $W$, Swanson RA. Poly(ADP-ribose) polymerase-1 mediated cell death in astrocytes required NAD + depletion and mitochondrial permeability transition. J Biol Chem. 2004; 279: 18895-18902.

89. Suh PG, Park J, Manzoli L, Cocco L, Peak JC, Katan M, et al. Multiple roles of phosphoinositide-specific phospholipase C isozymes. BMB Rep. 2008: 41: 415-434.

90. Fukami K, Inanobe S, Kanemaru K, Nakamura Y. Phospholipase C is a key enzyme regulating intracellular $\mathrm{Ca}^{2+}$ and modulating the phosphoinositide balance. Prog Lipid Res. 2010: 49: 429-437.

91. Popovics P, Stewart AJ. Phospholipase C- $\eta$ activity may contribute to Alzheimer's diseaseassociated $\mathrm{Ca}^{2+}$ opathy. J Alzheimers Dis. 2012; 30: 737-744.

92. Ueda Y. The role of phosphoinositides in synapse function. Mol Neurobiol. 2014; 50: 821-838.

93. Berridge MJ, Irvine RF. Inositol triphosphate, a novel second messenger in cellular signal transduction. Nature. 1984; 312: 315-321.

94. Balla T. Phosphoinositides: Tiny lipids with giant impact on cell regulation. Physiol Rev. 2013; 93: 1019-1137.

95. Waugh MG. PIPs in neurological diseases. Biochim Biophys Acta. 2015; 1851: 1066-1082.

96. Lo Vasco VR. The Phosphoinositide pathway and the signal transduction network in neural development. Neurosci Bull. 2012; 28: 789-800.

97. Katan M. New insights into the families of PLC enzymes: Looking back and going forward. Biochem J. 2005; 391: e7-e9.

98. Cockcroft S, Thomas GMH. Inositol-lipid-specific phospholipase $\mathrm{C}$ isoenzymes and their differential regulation by receptors. Biochem J. 1992; 288: 1-14.

99. Lo Vasco VR. Role of Phosphoinositide-specific Phospholipase C $\eta 2$ in isolated and syndromic mental retardation. Eur Neurol. 2011; 65: 264-269.

100. Wallace MA, Claro E. A novel role for dopamine: inhibition of muscarinic cholinergicstimulated phosphoinositide hydrolysis in rat brain cortical membranes. Neurosci Lett. 1990; 110: 155-161.

101. Kim D, Jun KS, Lee SB, Kang NG, Min DS, Kim YH, et al. Phospholipase C isozymes selectively couple to specific neurotransmitter receptors. Nature. 1997; 389: 290-293.

102. Choi WC, Gerfen CR, Suh PG, Rhee SG. Immunohistochemical localization of a brain isozyme of phospholipase C (PLC III) in astroglia in rat brain. Brain Res. 1989; 499: 193-197.

103. Kurian MA, Meyer E, Vassallo G, Morgan NV, Prakash N, Pasha S, et al. Phospholipase C beta 1 deficiency is associated with early-onset epileptic encephalopathy. Brain. 2010; 133: 29642970.

104. Lo Vasco VR, Cardinale G, Polonia P. Deletion of PLCB1 gene in schizophrenia affected patients. J Cell Mol Med. 2012; 16: 844-851.

105. Lo Vasco VR, Longo L, Polonia P. Phosphoinositide-specific Phospholipase C ß1 gene deletion in bipolar disorder affected patient. J Cell Commun Signal. 2013; 7: 25-29. 
106. Lo Vasco VR, Polonia P. Molecular cytogenetic interphase analysis of Phosphoinositidespecific Phospholipase $C \beta 1$ gene in paraffinembedded brain samples of major depression patients. J Affect Disord. 2012; 136: 177-180.

107. Ferreire PA, Pak WL. Bovine phospholipase C highly homologous to the norpA protein of Drosophila is expressed specifically in cones. J Biol Chem. 1994; 269: 3129-3131.

108. Heneka MT, Carson MJ, Khoury JE, Landreth GE, Brosseron F, Feinstein DL, et al. Neuroinflammation in Alzheimer's disease. Lancet Neurol. 2015; 14: 388-405.

109. Lo Vasco VR, Fabrizi C, Artico M, Cocco L, Billi AM, Fumagalli L, et al. Expression of phosphoinositide-specific phospholipase $C$ isoenzymes in cultured astrocytes. J Cell Biochem. 2007; 100: 952-959.

110. Lo Vasco VR, Fabrizi C, Panetta B, Fumagalli L, Cocco L. Expression pattern and sub cellular distribution of Phosphoinositide specific Phospholipase $C$ enzymes after treatment with $\mathrm{U}$ 73122 in rat astrocytoma cells. J Cell Biochem. 2010; 110: 1005-1012.

111. Lo Vasco VR. 1p36.32 rearrengements and the role of PI-PLC $\eta 2$ in nervous tumours. J Neurooncol. 2011; 103: 409-416.

112. Iqbal K, Grundke-Iqbal I. Metabolic/signal transduction hypothesis of Alzheimer's disease and other tauopathies. Acta Neuropathol. 2005; 109: 25-31.

113. Nelson TJ, Sun MK, Hongpaisan J, Alkon DL. Insulin. PKC signaling pathways and synaptic remodeling during memory storage and neuronal repair. Eur J Pharmacol. 2008; 585: 76-87.

114. Calderini G, Bonetti AC, Battistella A, Crews FT, Toffano G. Biochemical changes of rat brain membranes with aging. Neurochem Res. 1983; 8: 483-492.

115. Rivnay B, Globerson A, Shinitzky M. Viscosity of lymphocyte plasma membrane in aging mice and its possible relation to serum cholesterol. Mech Ageing Dev. 1979; 10: 71-79.

116. Pettegrew JW, Panchalingam K, Withers G, McKeag D, Strychor S. Changes in brain energy and phospholipid metabolism during development and aging in the Fischer 344 rat. J Neuropathol Exp Neurol. 1990; 49: 237-249.

117. Crews FT, Calderini G, Battistella A, Toffano G. Age dependent changes in the methylation of rat brain phospholipids. Brain Res. 1981; 229: 256-259.

118. Gaiti A, Brunetti M, Piccinin GL, Woelk H, Porcellati G. The synthesis in vivo of choline and ethanolamine phosphoglycerides in different brain areas during aging. Lipids. 1982; 17: 291296.

119. Svennerholm L, Boström K, Helander CG, Jungbjer B. Membrane lipids in the aging human brain. J Neurochem. 1991; 56: 2051-2059.

120. Stokes CE, Gillon KR, Hawthorne JN. Free and total lipid myoinositol concentrations decrease with age in human brain. Biochim Biophys Acta. 1983; 753: 136-138.

121. Dawson RM, Eichberg J. Diphosphoinositide and triphosphoinositide in animal tissues. Extraction, estimation and changes post mortem. Biochem J. 1965; 96: 634-643.

122. Zubenko GS. Hippocampal membrane alteration in Alzheimer's disease. Brain Res. 1986; 385: 115-121.

123. Pettegrew JW. Molecular insights into Alzheimer's disease[M]//Biological Markers of Alzheimer's Disease. Springer, Berlin, Heidelberg, 1989: 83-104.

124. Pettegrew JW, Klunk WE. In Imaging, cerebral topography and Alzheimer's disease (Rapoport, S.R, Petit, H, Leys, D. and Christen, Y, eds.). 1990; 159-165. 
125. Stokes CE, Hawthorne JN. Reduced phosphoinositide concentrations in anterior temporal cortex of Alzheimer-diseased brains. J Neurochem. 1987; 48: 1018-1021.

126. Eichberg J, Dawson RM. Polyphosphoinositides in myelin. Biochem J. 1965; 96: 644-650.

127. Jolles J, Bothmer J, Markerink M, Ravid R. Reduced phosphatidylinositol kinase activity in Alzheimer's disease: effects of age and onset. Dementia. 1993; 4: 81-86.

128. Bothmer J, Markerink $M$, Jolles J. Evidence for a selective decrease in type 1 phosphatidylinositol kinase activity in brains of patients with Alzheimer's disease. Dementia. 1994; 5: 6-11.

129. Young LT, Kish SJ, Li PP, Warsh JJ. Decreased brain [3H]inositol 1,4,5-trisphosphate binding in Alzheimer's disease. Neurosci Lett. 1988; 94: 198-202.

130. Colvin RA, Bennett JW, Colvin SL, Allen RA, Martinez J, Miner GD. Na+/Ca2+ exchange activity is increased in Alzheimer's disease brain tissues. Brain Res. 1991; 543: 139-147.

131. Gandy S, Czernik AJ, Greengard P. Phosphorylation of Alzheimer disease amyloid precursor peptide by protein kinase $\mathrm{C}$ and $\mathrm{Ca} 2+$ /calmodulin-dependent protein kinase II. Proc Natl Acad Sci USA. 1988; 85: 6218-6221.

132. Masliah E, Cole G, Shimohama S, Hansen L, DeTeresa R, Terry RD, et al. Differential involvement of protein kinase $C$ isozymes in Alzheimer's disease. J Neurosci. 1990; 10: 21132124.

133. Clark EA, Leach KL, Trojanowski JQ, Lee VM. Characterization and differential distribution of the three major human protein kinase $C$ isozymes (PKC alpha, PKC beta, and PKC gamma) of the central nervous system in normal and Alzheimer's dis ease brains. Lab Invest. 1991; 64: 35-44.

134. Masliah E, Cole GM, Hansen LA, Mallory M, Albright T, Terry RD, et al. Protein kinase C alteration is an early biochemical marker in Alzheimer's disease. J Neurosci. 1991; 11: 27592767.

135. Tanaka S, Tominaga M, Yasuda I, Kishimoto A, Nishizuka Y. Protein kinase C in rat brain synaptosomes. Beta II-subspecies as a major isoform associated with membrane-skeleton elements. FEBS Lett. 1991; 294: 267-270.

136. Cole G, Dobkins KR, Hansen LA, Terry RD, Saitoh T. Decreased levels of protein kinase $C$ in Alzheimer brain. Brain Res. 1988; 452: 165-174.

137. Cochet C, Gill GN, Meisenhelder J, Cooper JA, Hunter T. C-kinase phosphorylates the epidermal growth factor receptor and reduces its epidermal growth factor-stimulated tyrosine protein kinase activity. J Biol Chem. 1984; 259: 2553-2558.

138. Northwood IC, Davis RJ. Protein kinase C inhibition of the epidermal growth factor receptor tyrosine protein kinase activity is independent of the oligomeric state of the receptor. J Biol Chem. 1989; 264: 5746-5750.

139. Shapiro IP, Masliah E, Saitoh T. Altered protein tyrosine phosphorylation in Alzheimer's disease. J Neurochem. 1991; 56: 1154-1162.

140. Berridge MJ. Dysregulation of neural $\mathrm{Ca}^{2+}$ signalling in Alzheimer disease, bipolar disorder and schizophrenia. Prion. 2012; 6: 1-12.

141. Berridge MJ. Ca ${ }^{2+}$ regulation of neural rhythms, memory and Alzheimer's disease. J Physiol. 2014; 592: 281-293.

142. Albasanz JL, Dalfó E, Ferrer I, Martín M. Impaired metabotropic glutamate receptor/phospholipase $\mathrm{C}$ signaling pathway in the cerebral cortex in Alzheimer's disease and 
dementia with Lewy bodies correlates with stage of Alzheimer's-disease-related changes. Neurobiol Dis. 2005; 20: 685-693.

143. Tanino H, Shimohama S, Sasaki Y, Sumida Y, Fujimoto S. Increase in phospholipase C-delta1 protein levels in aluminumtreated rat brains. Biochem Biophys Res Commun. 2000; 271: 620625.

144. Shimohama S, Fujimoto S, Matsushima H, Takenawa T, Taniguchi T, Perry G, et al. Alteration of phospholipase C-delta protein level and specific activity in Alzheimer's disease. J Neurochem. 1995; 64: 2629-2634.

145. Matsushima H, Shimohama S, Kawamata J, Fujimoto S, Takenawa T, Kimura J. Reduction of platelet phospholipase C-delta1 activity in Alzheimer's disease associated with a specific apolipoprotein E genotype (epsilon3/epsilon3). Int J Mol Med. 1998; 1: 91-93.

146. Zhang D, Dhillon H, Prasad MR, Markesbery WR. Regional levels of brain phospholipase Cgamma in Alzheimer's disease. Brain Res. 1998; 811: 161-165.

147. Shimohama S, Homma Y, Suenaga T, Fujimoto S, Taniguchi T, Araki W, et al. Aberrant accumulation of phospholipase C-delta in Alzheimer brains. Am J Pathol. 1991; 139: 737-742.

148. van der Lee SJ, Conway OJ, Jansen I, Carrasquillo MM, Kleineidam L, van den Akker E, et al. A nonsynonymous mutation in PLCG2 reduces the risk of Alzheimer's disease, dementia with Lewy bodies and frontotemporal dementia, and increases the likelihood of longevity. Acta Neuropathol. 2019; 138: 237-250.

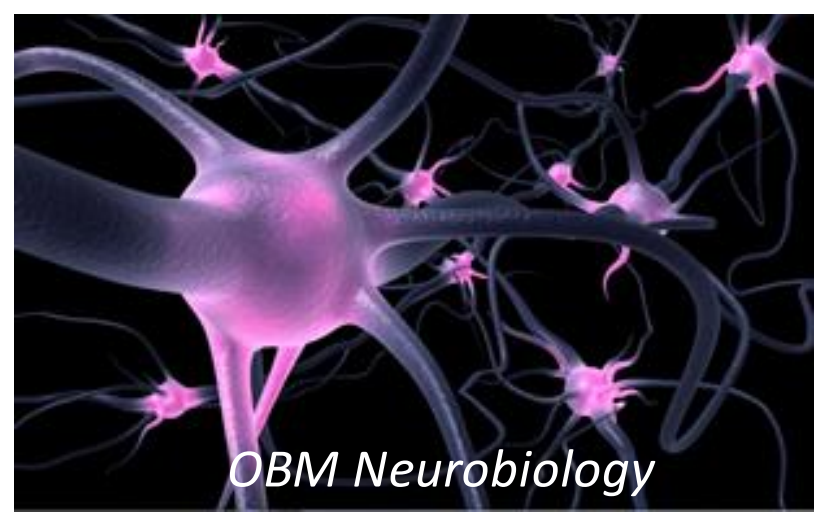

Enjoy OBM Neurobiology by:

1. Submitting a manuscript

2. Joining volunteer reviewer bank

3. Joining Editorial Board

4. Guest editing a special issue

For more details, please visit:

http://www.lidsen.com/journals/neurobiology 